\title{
Curcumin prevents lipopolysaccharide-induced matrix metalloproteinase-2 activity via the Ras/MEK1/2 signaling pathway in rat vascular smooth muscle cells
}

\author{
YI ZHONG, JIAN FENG, JIAFU LI and ZHONGCAI FAN \\ Department of Cardiology, The Affiliated Hospital of Luzhou Medical College, Luzhou, Sichuan 646000, P.R. China
}

Received December 7, 2015; Accepted January 16, 2017

DOI: $10.3892 / \mathrm{mmr} .2017 .7037$

\begin{abstract}
The aim of the present study was to examine the effect of curcumin treatment on lipopolysaccharide (LPS)-induced matrix metalloproteinase-2 (MMP-2) activity, and assess whether the effects are mediated by the Ras/mitogen-activated protein kinase kinase 1/2 (MEK1/2) signaling pathway in vascular smooth muscle cells (VSMCs). VSMCs were isolated from male Sprague-Dawley rats. Protein expression levels were analyzed by western blotting. The activity of MMP-2 was measured with gelatin zymography, and an electrophoretic mobility shift assay was used to detect the DNA binding activity of nuclear factor $-\kappa \mathrm{B}(\mathrm{NF}-\kappa \mathrm{B})$. Curcumin treatment was demonstrated to inhibit LPS-induced MMP-2 activity in rat VSMCs. This inhibitory effect was partially blocked by ammonium pyrrolidinedithiocarbamate, an inhibitor of $\mathrm{NF}-\kappa \mathrm{B}$ activation, and farnesylthiosalicylic acid, an inhibitor of Ras. In addition, the results of the present study indicated that LPS-induced phosphorylation of Ras homolog family member A and MEK $1 / 2$ was significantly decreased by curcumin. Furthermore, NF- $\kappa$ B p 65 expression in the nucleus and the DNA binding activity of $N F-\kappa B$ in rat LPS-exposed VSMCs was decreased by curcumin. Taken together, these findings suggest that curcumin prevents of LPS-induced MMP-2 activity through Ras/MEK1/2 and $\mathrm{NF}-\kappa \mathrm{B}$ signaling.
\end{abstract}

\section{Introduction}

Vascular remodeling caused by excessive accumulation of lipids in arteries is an important characteristic of the development of atherosclerotic plaques (1). Reconstruction of the vascular wall structure is determined by matrix metalloproteinases

Correspondence to: Dr Yi Zhong, Department of Cardiology, The Affiliated Hospital of Luzhou Medical College, 25 Tai Ping Street, Luzhou, Sichuan 646000, P.R. China

E-mail: zhongyi1982529@163.com

Key words: curcumin, matrix metalloproteinase-2, Ras/mitogen-activated protein kinase kinase 1/2 signaling pathway, nuclear factor- $\kappa \mathrm{B}$
(MMPs), and the majority of the extracellular matrix (ECM) is degraded by MMPs (2). According to a previous study, MMP-2 is involved in normal and pathological alterations in blood vessels (3). This previous study demonstrated that the expression of MMP-2 in vascular smooth muscle cells (VSMCs) was closely associated with certain pathological conditions, in particular atherosclerotic plaques. In vulnerable plaques the expression levels and activation of MMP-2 was significantly increased, indicating a pathogenic involvement of MMP-2 in the progression of atherosclerosis (4-6).

Curcumin, one of the active ingredients obtained from the spice turmeric, has multiple biological activities including anti-inflammatory, antioxidant and anticancer effects $(7,8)$. Previous studies have demonstrated that curcumin inhibits the expression and activity of MMP-2 under various experimental conditions and in different cell types. $(9,10)$. However, the potential molecular mechanisms underlying this remain to be elucidated.

In the present study, the effect of curcumin on lipopolysaccharide (LPS)-induced MMP-2 activity was investigated, as well as the associated underlying mechanisms. The results demonstrated that curcumin prevents LPS-induced MMP-2 activity through the Ras/mitogen-activated protein kinase kinase $1 / 2(\mathrm{MEK} 1 / 2)$ and nuclear factor- $\kappa \mathrm{B}(\mathrm{NF}-\kappa \mathrm{B})$ signaling pathways in VSMCs.

\section{Materials and methods}

Cell culture and treatment. Rat aortic VSMCs were isolated from male Sprague-Dawley rats, as described previously (11). Rats (age, 50 days; weight, 150-180 g; n=20) were purchased from the Laboratory Animal Center of Southern Medical University (Guangzhou, China) and were kept in the dark at temperature of $20-25^{\circ} \mathrm{C}$ with free access to food and water. The study was conducted in strict accordance with the recommendations in the Guide for the Care and Use of Laboratory Animals of the National Institutes of Health. This study was approved by the Ethics Committee of Southwest Medical University (Luzhou, China). Rats were sacrificed in order to isolate the VSMCs by injection with a fatal dose of $4 \%$ pentobarbital (Beyotime Institute of Biotechnology, Shanghai, China). Cells were cultured in Dulbecco's modified Eagle's medium (Gibco; Thermo Fisher Scientific, Inc., Waltham, MA, USA) containing $10 \%$ fetal bovine serum (Gibco; Thermo 
Fisher Scientific, Inc.), $100 \mathrm{U} / \mathrm{ml}$ penicillin and $100 \mu \mathrm{g} / \mathrm{ml}$ streptomycin at $37^{\circ} \mathrm{C}$ in a humidified $5 \% \mathrm{CO}_{2}$ atmosphere.

Cells were divided into four treatment groups as follows: Control, LPS-exposed, LPS + $20 \mu \mathrm{M}$ curcumin and LPS + $40 \mu \mathrm{M}$ curcumin. Cells were stimulated with curcumin (20 or $40 \mu \mathrm{M})$ in serum-free DMEM at $37^{\circ} \mathrm{C}$ for $1 \mathrm{~h}$, and exposed to $1 \mu \mathrm{g} / \mathrm{ml}$ LPS for an additional $3 \mathrm{~h}$ at $37^{\circ} \mathrm{C}$. The control cells were subjected to the same treatment, but PBS was used instead of curcumin and LPS. For subsequent experiments, cells were pretreated with $10 \mu \mathrm{M}$ ammonium pyrrolidinedithiocarbamate (PDTC) or $20 \mu \mathrm{M}$ farnesylthiosalicyclic acid (FTS) for $1 \mathrm{~h}$ at $37^{\circ} \mathrm{C}$, followed by exposure to $1 \mu \mathrm{g} / \mathrm{ml}$ LPS for $3 \mathrm{~h}$. The control cells were subjected to the same treatment, but PBS was used instead of PDTC and FTS. In subsequent experiments, cells were pretreated with 20 or $40 \mu \mathrm{M}$ curcumin for $1 \mathrm{~h}$, and exposed to $1 \mu \mathrm{g} / \mathrm{ml}$ LPS for an additional $3 \mathrm{~h}$.

MMP-2 activity assay. The enzymatic activity of MMP-2 was determined by gelatin zymography (12). Proteins were extracted from cells using radioimmunoprecipitation lysis buffer (Santa Cruz Biotechnology, Inc., Dallas, TX, USA) for $40 \mathrm{~min}$ on ice and centrifuged at $15,000 \mathrm{x} \mathrm{g}$ for $15 \mathrm{~min}$ at $4^{\circ} \mathrm{C}$, following which $50 \mathrm{mg}$ protein was separated by $11 \%$ SDS-PAGE at $4^{\circ} \mathrm{C}$. Gels were incubated with collagenase buffer and stained with Coomassie brilliant blue, followed by destaining with $30 \%$ isopropanol in $10 \%$ acetic acid. The images were visualized by Kodak Image Station 2000R (Kodak, Rochester, NY, USA) and densitometric analysis was conducted with Image J software version 1.38 (National Institutes of Health, Bethesda, MD, USA).

Western blotting. Proteins were extracted from cells using radioimmunoprecipitation lysis buffer for $30 \mathrm{~min}$ at $4{ }^{\circ} \mathrm{C}$. The protein content was determined using a Bicinchoninic Acid Protein Assay kit (Sigma-Aldrich; Merck Millipore, Darmstadt, Germany). Total proteins (50 $\mu \mathrm{g}$ per lane) were separated by $10 \%$ SDS-PAGE and transferred onto nitrocellulose membranes. Membranes were blocked with $8 \%$ skimmed milk in TBS buffer, followed by overnight incubation at $4^{\circ} \mathrm{C}$ with primary antibodies and washing prior to incubation for $2 \mathrm{~h}$ at room temperature with a goat anti-rabbit horseradish peroxidase-conjugated $\mathrm{IgG}$ secondary antibody (catalog no. SAB5300163; Sigma-Aldrich; Merck Millipore; 1:1,000). The following rabbit primary antibodies were purchased from Santa Cruz Biotechnology, Inc.: anti-Ras homolog family member A (RhoA; catalog no. SAB2102002; 1:2,000), anti-phosphorylated (p)-RhoA (catalog no. SAB4503986; 1:2,000), anti-p-MEK1/2 (catalog no. SAB4504466; 1:2,000) and anti-MEK1/2 (catalog no. MFCD00239713; 1:2,000). Rabbit polyclonal anti-NF- $\mathrm{B}$ p65 (catalog no. AF0246; $1: 1,000)$ and anti- $\beta$-actin (catalog no. AA128; $1: 1,000)$ were purchased from Beyotime Institute of Biotechnology (Haimen, China). The bands were visualized using an Enhanced Chemiluminescence system (GE Healthcare Life Sciences, Chalfont, UK), and the band density was determined by Image J software version 1.38.

Preparation of nuclear proteins. Nuclear proteins were extracted from cells as previously described (9). Protein content was determined using a Bicinchoninic Acid Protein assay reagent (Beyotime Institute of Biotechnology).

Electrophoretic mobility shift assay (EMSA). EMSA was performed as previously described (13). The nuclear extracts were incubated with a ${ }^{32} \mathrm{P}$-endlabeled double-stranded $\mathrm{NF}-\kappa \mathrm{B}$ oligonucleotide containing a tandem repeat consensus sequence of 5'-AGTTGAGGGGACTTTCCCAGGC-3', and were separated by electrophoresis on $4 \%$ polyacrylamide gels. The radioactive bands on the dried gels were quantified by a PhosphorImager using ImageQuant software version 5.1 (Molecular Dynamics, Inc., Sunnyvale, CA, USA).

Statistical analysis. All data are presented as the mean \pm standard deviation of three independent experiments. Statistical analysis was performed using one-way analysis of variance followed by Tukey's post hoc test. All statistical analyses were conducted using SPSS software version 13.0 (SPSS, Inc., Chicago, IL, USA). $\mathrm{P}<0.05$ was considered to indicate a statistically significant difference.

\section{Results}

Curcumin inhibits MMP-2 activity induced by LPS. MMP-2 activity significantly increased following exposure to LPS compared with the unexposed control $(\mathrm{P}<0.05$; Fig. 1) but pre-treatment with 20 and $40 \mathrm{uM}$ curcumin significantly decreased MMP-2 activity compared with the LPS-exposed group $(\mathrm{P}<0.05$ and $\mathrm{P}<0.05$, respectively; Fig. 1).

Ras/MEK1/2 signaling pathway mediates the increase of $M M P-2$ activity induced by LPS. To further investigate whether the Ras/MEK1/2 signaling pathway mediates the LPS-induced increase in MMP-2 activity, cells were pretreated with the inhibitors of NF- $\mathrm{NB}$ and Ras, PDTC and FTS. Compared with exposure to LPS alone, PDTC and FTS pretreatment significantly reduced LPS-induced MMP-2 activity $(\mathrm{P}<0.05$ and $\mathrm{P}<0.05$, respectively; Fig. 2).

Curcumin prevents the LPS-induced increase in MMP-2 activity via the Ras/MEK1/2 pathway. Various lines of evidence have suggested that the Ras/MEK1 pathway is involved in the activation of MMPs (14). To elucidate the possible underlying mechanisms, this signaling pathway was investigated in the present study. The results revealed that 20 and $40 \mu \mathrm{M}$ curcumin treatment significantly inhibited LPS-induced activation of $\mathrm{p}-\mathrm{RhoA}$ compared with the LPS-exposed group $(\mathrm{P}<0.05$ and $\mathrm{P}<0.05$, respectively; Fig. 3A). In addition, MEK1, a key effector of Ras in the regulation of MMPs, was examined. Treatment with 20 and $40 \mu \mathrm{M}$ curcumin suppressed LPS-induced activation of p-MEK1/2 compared with the LPS-exposed group $(\mathrm{P}<0.05$ and $\mathrm{P}<0.05$, respectively; Fig. 3B).

Curcumin inhibits LPS-induced $N F-\kappa B$ activity. The Ras/MEK1 signaling pathway is involved the activity of $\mathrm{NF}-\kappa \mathrm{B}$ in MMP transcription (15). In addition, a previous study demonstrated that $\mathrm{NF}-\kappa \mathrm{B}$ is involved in regulating MMP-2 at the transcriptional level (16). Therefore, it was hypothesized that curcumin prevents LPS-induced increases 

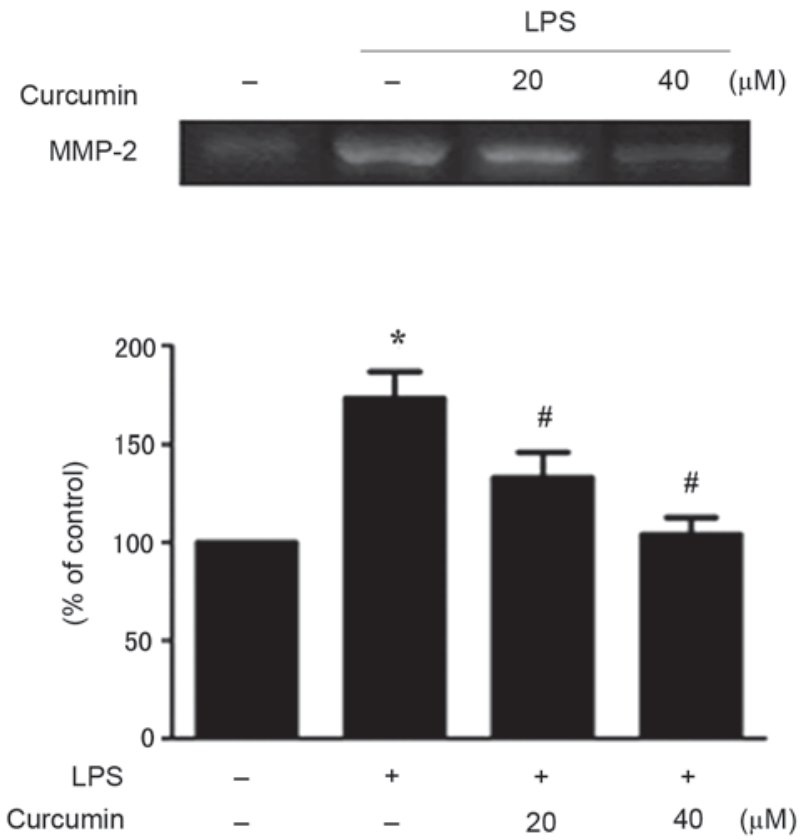

Figure 1. Curcumin inhibits LPS-induced MMP-2 activity in rat vascular smooth muscle cells, as measured by gelatin zymography. ${ }^{*} \mathrm{P}<0.05$ vs. control; ${ }^{\#} \mathrm{P}<0.05$ vs. LPS only. Data are expressed as the mean \pm standard deviation of three independent experiments. LPS, lipopolysaccharide; MMP-2, matrix metalloproteinase-2.

MMP-2
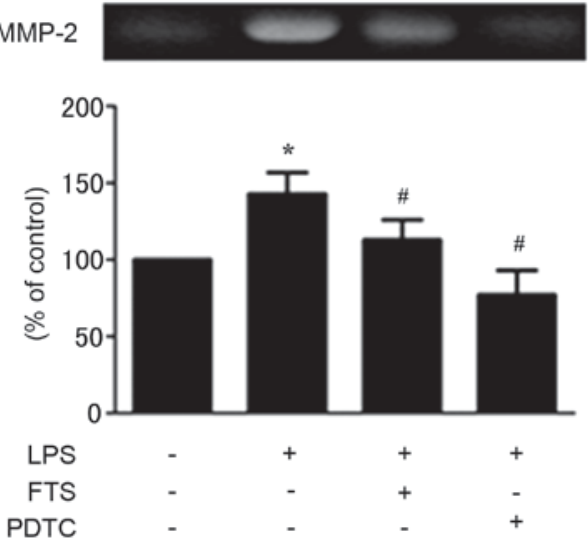

Figure 2. Ras/MEK1/2 signaling pathway is involved in the LPS-induced increase in MMP-2 activity. MMP-2 activity was assessed by gelatin zymography following treatment with LPS and the nuclear factor- $\mathrm{\kappa B}$ inhibitor PDTC or the Ras inhibitor FTS. ${ }^{*} \mathrm{P}<0.05$ vs. control; ${ }^{*} \mathrm{P}<0.05$ vs. LPS only. Data are expressed as the mean \pm standard deviation of three independent experiments. MEK1/2, mitogen-activated protein kinase kinase 1/2; LPS, lipopolysaccharide; MMP-2, matrix metalloproteinase-2; FTS, farnesylthiosalicyclic acid; PDTC, ammonium pyrrolidinedithiocarbamate.

in MMP-2 activity via the suppression of NF- $\kappa \mathrm{B}$ activation. The results of the present study indicated that LPS exposure significantly increased $\mathrm{NF}-\kappa \mathrm{B}$ p 65 protein expression levels compared with the control group $(\mathrm{P}<0.05$; Fig. 4A); however, this increase was significantly inhibited by treatment with 20 and $40 \mu \mathrm{M}$ curcumin compared with the LPS-exposed group $(\mathrm{P}<0.05$ and $\mathrm{P}<0.05$, respectively; Fig. 4A).

In addition, LPS exposure significantly increased the DNA binding activity of $\mathrm{NF}-\kappa \mathrm{B}$ compared with the control group $(\mathrm{P}<0.05$; Fig. 4B); however, this effect was significantly
A

$$
\text { p-RhoA }
$$

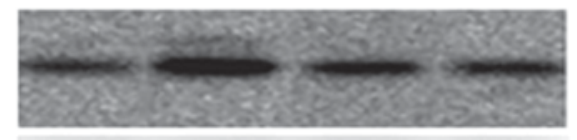

Total RhoA
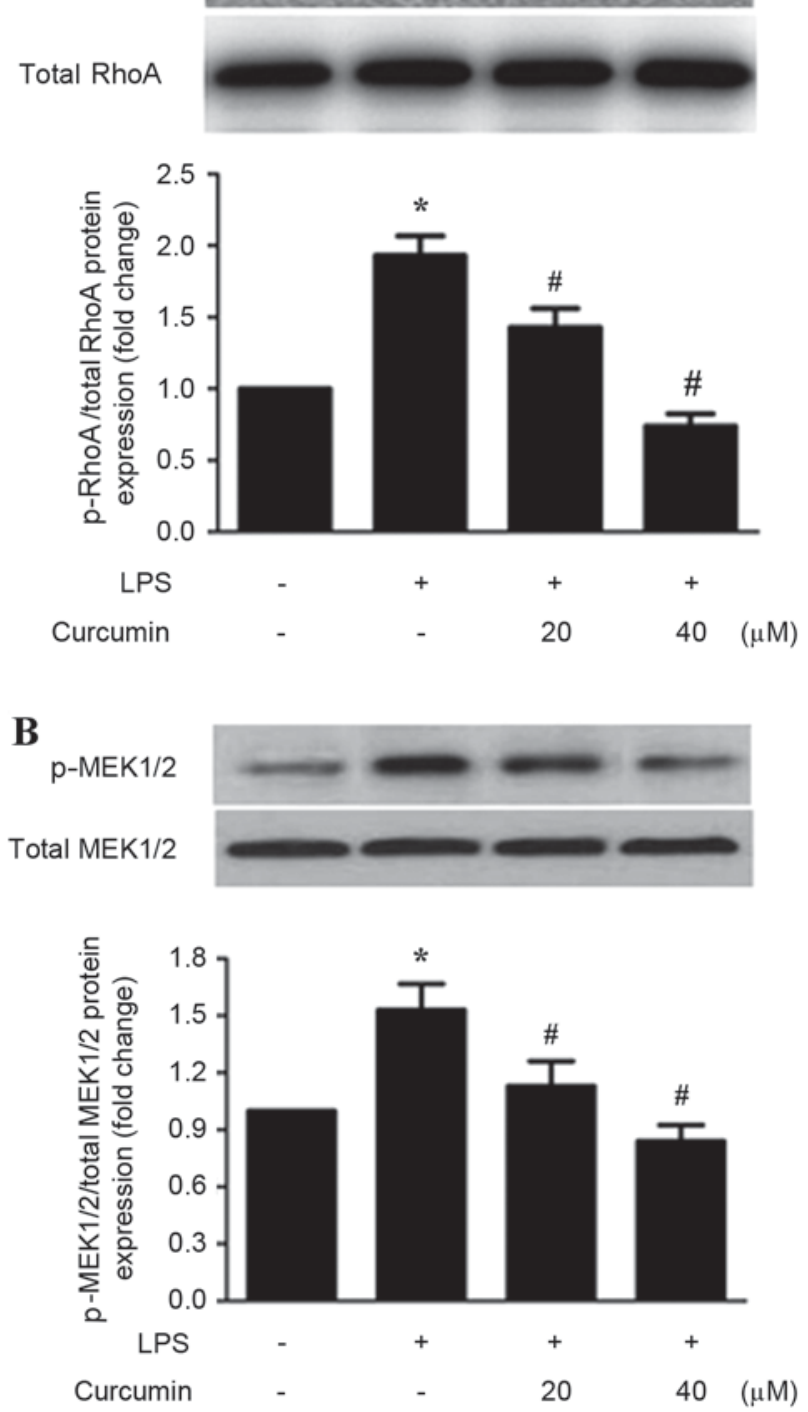

Figure 3. Curcumin prevents the LPS-induced increase of matrix metalloproteinase-2 activity via the Ras/MEK1/2 signaling pathway. Cells were pretreated with 20 or $40 \mu \mathrm{M}$ curcumin for $1 \mathrm{~h}$, and exposed to $1 \mu \mathrm{g} / \mathrm{ml}$ LPS for an additional $3 \mathrm{~h}$. (A) LPS-induced phosphorylation of RhoA was significantly inhibited by curcumin. (B) LPS-induced phosphorylation of MEK1/2 was significantly inhibited by curcumin. ${ }^{*} \mathrm{P}<0.05$ vs. control; ${ }^{\mathrm{P}} \mathrm{P}<0.05$ vs. LPS only. Data are expressed as the mean \pm standard deviation of three independent experiments. LPS, lipopolysaccharide; MEK1/2, mitogen-activated protein kinase kinase 1/2; RhoA, Ras homolog family member A; p, phosphorylated.

inhibited by treatment with 20 and $40 \mu \mathrm{M}$ curcumin compared with the LPS-exposed group $(\mathrm{P}<0.05$ and $\mathrm{P}<0.05$, respectively; Fig. 4B).

\section{Discussion}

VSMC migration to the vascular intima and ECM remodeling are important steps in the development of atherosclerosis (17). In this process, the abnormal secretion and activation of MMPs (in particular, MMP-2) and tissue inhibitors of metalloproteinases (TIMPs; in particular TIMP-2) in rat VSMCs leads to an altered balance between the two, resulting in the 

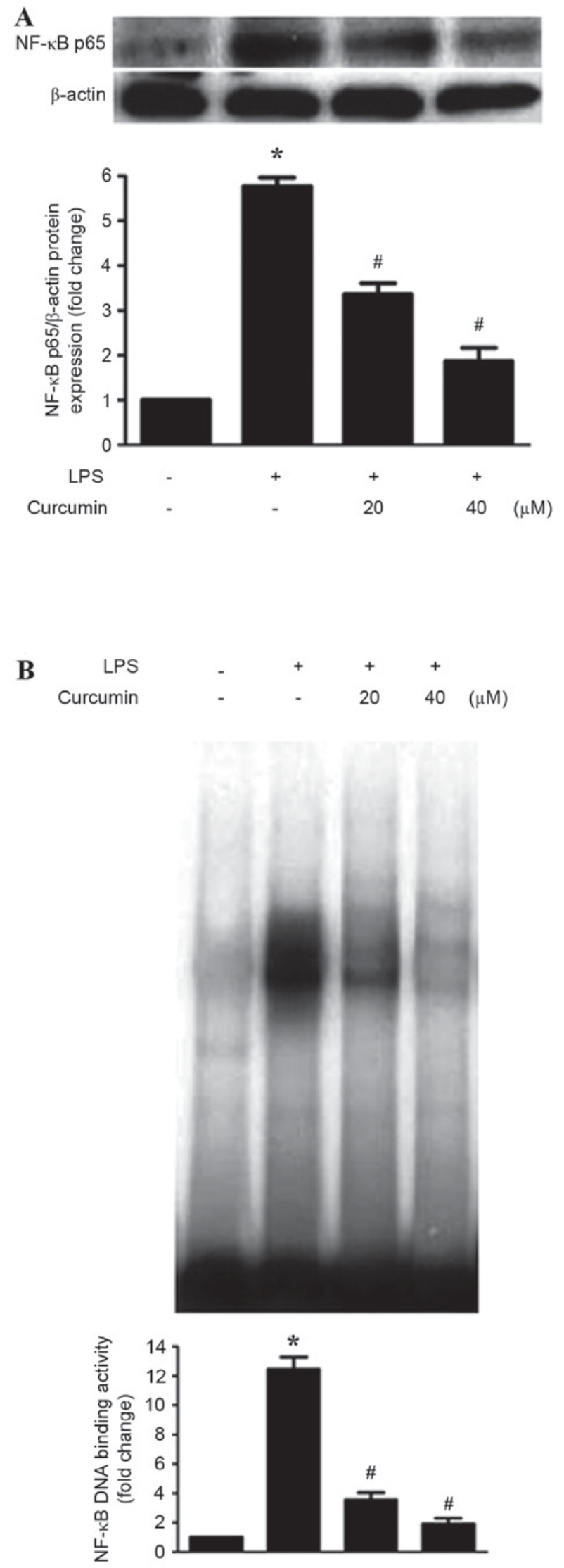

Figure 4. Curcumin suppresses NF-kB DNA binding activity. Cells were pretreated with 20 or $40 \mu \mathrm{M}$ curcumin for $1 \mathrm{~h}$, and exposed to $1 \mu \mathrm{g} / \mathrm{ml}$ LPS for an additional $3 \mathrm{~h}$. (A) Curcumin inhibited the LPS-induced increase of NF- $\kappa \mathrm{B}$ p65 subunit protein expression levels in the nucleus. (B) Curcumin inhibits NF- $\kappa B$ DNA binding activity. ${ }^{*} \mathrm{P}<0.05$ vs. control; ${ }^{\#} \mathrm{P}<0.05$ vs. LPS only. Data are expressed as the mean \pm standard deviation of three inde-

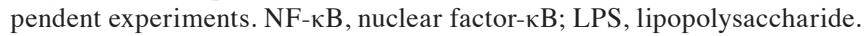

remodeling of the ECM (18). Thus, it is important to reduce the activation and expression of MMP-2 in rat VSMCs.

In the present study, curcumin was demonstrated to inhibit LPS-induced MMP-2 activity, and the potential underlying mechanisms were identified. LPS is released from Gram-negative bacteria and promotes atherosclerosis in humans by aggravating the inflammatory response in the arterial wall (19). The present study revealed that curcumin inhibited LPS-induced increases in MMP-2 activity, which is consistent with a previous report (9). MMP-2 expression is induced by cytokines, hormones and growth factors and is regulated by the activation or suppression of promoter activity (20-22). A previous study demonstrated that overexpression of mitogen activated protein kinase (MAPK) phosphatases with selective dual specificity suppresses the activation of the MMP promoter, which is a more effective way to inhibit the activation of the transcription factors activator protein-1 (AP-1), E-twenty-six (ETS) and the MMP promoter (23). The DNA binding and transcription ability of the AP-1 and ETS transcription factors is regulated by phosphorylation of MAPKs and serine/threonine kinase, which mediate cell-cell and cell-matrix interactions induced by various stimulating factors. (24-26) Ras activation may further activate ETS-1 and -2, and ERK1/2 and c-Jun N-terminal kinase/stress activated protein kinase signaling pathways (27). Therefore, the involvement of the Ras/MEK1/2 signaling pathway in the LPS-induced increase in MMP-2 activity was investigated. The results indicated that the LPS-induced increase in MMP-2 activity may be suppressed by PDTC and FTS. Similarly, a previous study demonstrated that inhibitors of RhoA and NF-kB inhibited LPS-induced increase of MMP-2 activity (28). In addition, the results of the present study demonstrated that LPS-induced increased expression levels of p-RhoA and p-MEK1/2 were significantly suppressed by curcumin treatment. These results indicated that curcumin prevents the LPS-induced increased MMP-2 activity via the Ras/MEK1/2 signaling pathway.

The activation of $N F-\kappa B$ is required for MMP expression (29). Inactive $\mathrm{NF}-\kappa \mathrm{B}$ is presented as a heterodimeric complex of the subunits p50 and p65, which combine with inhibitor of $\kappa \mathrm{B}(\mathrm{I} \kappa \mathrm{B})$ in cells. When the cell is stimulated, $\mathrm{I} \kappa \mathrm{B}$ is degraded via phosphorylation. The liberated $\mathrm{NF}-\kappa \mathrm{B}$ translocates to the nucleus, where the dimer interacts with regulatory $\kappa \mathrm{B}$ elements in promoters and enhancers, thereby controlling gene transcription (30). The activity of $N F-\kappa B$ in MMP transcription is regulated by the Ras/MEK1 signaling pathway (15). In the present study, NF- $\kappa \mathrm{B}$ p65 expression was inhibited by curcumin treatment in rat VSMCs. The DNA binding activity of NF- $\kappa \mathrm{B}$ was significantly increased by LPS; however, this effect was partially suppressed by treatment with curcumin. These findings are in accordance with another previous study (31).

In conclusion, the results of the present study demonstrated that curcumin treatment significantly inhibited LPS-induced MMP-2 activity in rat VSMCs. Inhibitors of NF- $\kappa \mathrm{B}$ and Ras suppressed LPS-induced increased MMP-2 activity. The results indicated that curcumin significantly inhibited LPS-induced activation of $\mathrm{p}-\mathrm{RhoA}$ and $\mathrm{p}-\mathrm{MEK} 1 / 2$ in rat VSMCs. The expression of $\mathrm{NF}-\kappa \mathrm{B}$ p 65 was additionally inhibited by curcumin. Furthermore, the LPS-induced increase in NF- $\kappa \mathrm{B}$ 
DNA binding activity was abrogated by curcumin treatment. These results suggested that curcumin prevents LPS-induced MMP-2 activity via the Ras/MEK1/2 signaling pathway in rat VSMCs. Therefore, curcumin may be a potential therapeutic agent for the treatment of cardiovascular disease.

\section{Acknowledgements}

The present study was supported by Luzhou Medical College (grant no. 20130337).

\section{References}

1. Visse R and Nagase H: Matrix metalloproteinases and tissue inhibitors of metalloproteinases: Structure, function, and biochemistry. Circ Res 92: 827-839, 2003.

2. Galis ZS and Khatri JJ: Matrix metalloproteinases in vascular remodeling and atherogenesis: The good, the bad and the ugly. Circ Res 90: 251-262, 2002.

3. Risinger GM Jr, Hunt TS, Updike DL, Bullen EC and Howard EW: Matrix metalloproteinase-2 expression by vascular smooth muscle cells is mediated by both stimulatory and inhibitory signals in response to growth factors. J Biol Chem 281: 25915-25925, 2006.

4. Shah PK and Galis ZS: Matrix metalloproteinase hypothesis of plaque rupture: Players keep piling up but questions remain. Circulation 104: 1878-1880, 2001.

5. Newby AC and Zaltsman AB: Fibrous cap formation or destruction-the critical importance of vascular smooth muscle cell proliferation, migration and matrix formation. Cardiovasc Res 41: 345-360, 1999.

6. Caird J, Napoli C, Taggart C, Farrell M and Bouchier-Hayes D: Matrix metalloproteinases 2 and 9 in human atherosclerotic and non-atherosclerotic cerebral aneurysms. Eur J Neurol 13: 1098-1105, 2006.

7. Guo LY, Cai XF, Lee JJ, Kang SS, Shin EM, Zhou HY, Jung JW and Kim YS: Comparison of suppressive effects of demethoxycurcumin and bisdemethoxycurcumin on expressions of inflammatory mediators in vitro and in vivo. Arch Pharm Res 31 490-496, 2008.

8. Kunnumakkara AB, Anand P and Aggarwal BB: Curcumin inhibits proliferation, invasion, angiogenesis and metastasis of different cancers through interaction with multiple cell signaling proteins. Cancer Lett 269: 199-225, 2008.

9. Zhong Y, Yu W, Feng J, Fan Z and Li J: Curcumin suppresses tumor necrosis factor- $\alpha$-induced matrix metalloproteinase- 2 expression and activity in rat vascular smooth muscle cells via the NF- $\kappa B$ pathway. Exp Ther Med 7: 1653-1658, 2014.

10. Liang Y, Huang M, Li J, Sun X, Jiang X, Li L and Ke Y: Curcumin inhibits vasculogenic mimicry through the downregulation of erythropoietin-producing hepatocellular carcinoma-A2, phosphoinositide 3-kinase and matrix metalloproteinase-2. Oncol Lett 8: 1849-1855, 2014.

11. Kamimura M, Bea F, Akizawa T, Katus HA, Kreuzer J and Viedt C: Platelet-derived growth factor induces tissue factor expression in vascular smooth muscle cells via activation of Egr-1. Hypertension 44: 944-951, 2004.

12. Demeule M, Brossard M, Pagé M, Gingras D and Béliveau R: Matrix metalloproteinase inhibition by green tea catechins. Biochim Biophys Acta 1478: 51-60, 2000.

13. Takada Y, Khuri FR and Aggarwal BB: Protein farnesyltransferase inhibitor (SCH 66336) abolishes NF-kappaB activation induced by various carcinogens and inflammatory stimuli leading to suppression of NF-kappaB-regulated gene expression and up-regulation of apoptosis. J Biol Chem 279: 26287-26299, 2004.
14. Liu E, Thant AA, Kikkawa F, Kurata H, Tanaka S, Nawa A, Mizutani S, Matsuda S, Hanafusa $\mathrm{H}$ and Hamaguchi M: The Ras-mitogen-activated protein kinase pathway is critical for the activation of matrix metalloproteinase secretion and the invasiveness in v-crk-transformed 3Y1. Cancer Res 60: 2361-2364, 2000.

15. Kim SE, Thanh Thuy TT, Lee JH, Ro JY, Bae YA, Kong Y, Ahn JY, Lee DS, Oh YM, Lee SD and Lee YS: Simvastatin inhibits induction of matrix metalloproteinase-9 in rat alveolar macrophages exposed to cigarette smoke extract. Exp Mol Med 41: 277-287, 2009.

16. Wu X and Li L: Rosiglitazone suppresses lipopolysaccharide-induced matrix metalloproteinase- 2 activity in rat aortic endothelial cells via Ras-MEK1/2 signaling. Int J Cardiol 158: 54-58, 2012.

17. Weber $\mathrm{C}$ and Noels $\mathrm{H}$ : Atherosclerosis: Current pathogenesis and therapeutic options. Nat Med 17: 1410-1422, 2011.

18. Löffek S, Schilling $O$ and Franzke CW: Series 'matrix metalloproteinases in lung health and disease': Biological role of matrix metalloproteinases: A critical balance. Eur Respir J 38: 191-208, 2011.

19. Westerterp M, Berbée JF, Pires NM, van Mierlo GJ, Kleemann R, Romijn JA, Havekes LM and Rensen PC: Apolipoprotein C-I is crucially involved in lipopolysaccharide-induced atherosclerosis development in apolipoprotein E-knockout mice. Circulation 116: 2173-2181, 2007.

20. Mukherjee R, Mingoia JT, Bruce JA, Austin JS, Stroud RE, Escobar GP, McClister DM Jr, Allen CM, Alfonso-Jaume MA, Fini ME, et al: Selective spatiotemporal induction of matrix metalloproteinase-2 and matrix metalloproteinase- 9 transcription after myocardial infarction. Am J Physiol Heart Circ Physiol 291: H2216-H2228, 2006.

21. Tyagi SC, Kumar S and Katwa L: Differential regulation of extracellular matrix metalloproteinase and tissue inhibitor by heparin and cholesterol in fibroblast cells. J Mol Cell Cardiol 29: 391-404, 1997.

22. Stygar D, Wang H, Vladic YS, Ekman G, Eriksson H and Sahlin L: Increased level of matrix metalloproteinases 2 and 9 in the ripening process of the human cervix. Biol Reprod 67: 889-894, 2002.

23. Chakraborti S, Mandal M, Das S, Mandal A and Chakraborti T: Regulation of matrix metalloproteinases: An overview. Mol Cell Biochem 253: 269-285, 2003.

24. Minden A and Karin M: Regulation and function of the JNK subgroup of MAP kinases. Biochim Biophys Acta 1333: F85-F104, 1997.

25. Robinson MJ and Cobb MH: Mitogen-activated protein kinase pathways. Curr Opin Cell Biol 9: 180-186, 1997.

26. Lewis TS, Shapiro PS and Ahn NG: Signal transduction through MAP kinase cascades. Adv Cancer Res 74: 49-139, 1998.

27. O'Hagan RC, Tozer RG, Symons M, McCormick F and Hassell JA: The activity of the Ets transcription factor PEA3 is regulated by two distinct MAPK cascades. Oncogene 13: 1323-1333, 1996.

28. Yoo T, Ham SA, Hwang JS, Lee WJ, Paek KS, Oh JW, Kim JH, Do JT, Han CW, Kim JH and Seo HG: Peroxisome proliferator-activated receptor $\delta$ inhibits Porphyromonas gingivalis lipopolysaccharide-induced activation of matrix metalloproteinase- 2 by downregulating NADPH oxidase 4 in human gingival fibroblasts. Mol Oral Microbiol 31: 398-409, 2016.

29. Vincenti MP and Brinckerhoff CE: Transcriptional regulation of collagenase (MMP-1, MMP-13) genes in arthritis: Integration of complex signaling pathways for the recruitment of gene-specific transcription factors. Arthritis Res 4: 157-164, 2002.

30. Hayden MS and Ghosh S: Signaling to NF-kappaB. Genes Dev 18: 2195-2224, 2004.

31. Meng Z, Yan C, Deng Q, Gao DF and Niu XL: Curcumin inhibits LPS-induced inflammation in rat vascular smooth muscle cells in vitro via ROS-relative TLR4-MAPK/NF- $\kappa$ B pathways. Acta Pharmacol Sin 34: 901-911, 2013. 